\title{
ileri Evre Parkinson Hastalığında Subkutan Apomorfin Klinik Deneyimlerimiz
}

\author{
Clınıcal Experıences of Subkutan Apomorphıne in Advanced Stage \\ Parkınson Disease
}

\author{
Yeşim Güzey Aras, Türkan Acar \\ Sakarya Üniversitesi Eğitim ve Araşıırma Hastanesi Nöroloji A.D.
}

Yazışma Adresi / Correspondence:

Yeşim Güzey Aras

Sakarya Üniversitesi Eğitim ve Araştırma Hastanesi Nöroloji Kliniği /SAKARYA

T: +90 5057461439 E-mail: yesimguzeyaras@hotmail.com

Geliş Tarihi / Received : 17.05.2018 Kabul Tarihi / Accepted : 28.05.2018

\footnotetext{
Öz

Amaç Parkinson Hastalığı (PH) bazal ganglionlardaki substansia nigranın pars kompaktasındaki dopaminerjik nöron kaybı ile giden ve oral dopaminerjik preparatlarla tedavi edilen bir hastalıktır. Ancak ileri Evre Parkinson Hastalı̆ı (iEPH)'inda oral dopaminerjik tedavi seçeneklerine klinik yanıtın azalması Subkutan Apomorfin Tedavisine (SAT) olan ilgiyi artırmıştır. Bu çalışmada kliniğimizde iEPH'da 5 yıllık süre boyunca SAT uygulanan hastaların verileri sunulmaktadır.( Sakarya Tip Dergisi, 2018, 8(2):254-259 )

Gereç ve Bu çalışmada kliniğimizde United Kingdom Parkinson's Disease Society Brain Bank (UKPDSBB) tanı kriterlerine göre tanı konulan ve SAT

Yöntem alan 28 iEPH'nın dosyaları retrospektif olarak incelendi. Hastaların demografik verileri, hastalık başlama yaşı, hastalık süresi, uygulama öncesi Hoehn-Yahr (H\&Y) evresi, Birleşik Parkinson Derecelendirme Ölçeği (UPDRS-Unified Parkinson's Disease Rating Scale) motor skorları, günlük total of süreleri, diskinezi şiddeti, günlük kullanılan total levodopa dozları, apomorfin dozu, kullanım süresi, kullanım şekli kaydedildi ve uygulama öncesi ve sonrası değerler birbiri ile karşış̧ııııldı.

Bulgular Çalışmaya alınan hastaların 16'sı erkek, 12 'si kadın cinsiyette idi. Ortalama hastalık başlama yaşı $63,4 \pm 4,9$ hastalık süresi 10,1 $\pm 2,8$ yıl idi. Ortalama günlük total SAT dozu $53,5 \pm 18,9$ mg kullanım süresi $17,6 \pm 9$ ay idi. Uygulama öncesi en iyi on döneminde yapılan nörolojik muayenede ortalama of süresi $4,4 \pm 1,6$ saat iken uygulama sonrası ortalama of süresi $1,1 \pm 0,3$ saat idi ve istatistiksel olarak anlamlı fark saptandı $(p<0,001)$. Uygulama öncesi ve sonrası en iyi on döneminde yapılan muayenede ortalama diskinezi şiddeti, UPDRS motor skorları ve ortalama levodopa dozlarında istatistiksel olarak anlamlı fark saptanmıştır.(sırasıyla $p<0,001, p<0,001, p<0,001)$

Sonuç SAT'si IEPH'da UPDRS skorlarında, levodopa dozunun azaltılmasında, of sürelerinin kısaltılmasında ve diskinezilerin azaltılmasında etkilidir.

Anahtar Parkinson Hastalığ; Apomorfin; of süresi; diskinezi

Kelimeler
}

\section{Abstract}

Objective Parkinson's Disease (PH) is disease caused by dopaminergic neuron loss in pars compacta of substantia nigra in basal ganglia and treated with oral dopaminergic preparations. However, 2 reduction in clinical response to oral dopaminergic treatment options Advanced Phase Parkinson's Disease (APPD) has increased interest in subcutaneous apomorphine treatment (SAT). In this study, we present data of patients who underwent SAT for 5 years APPD our clinic. ( Sakarya Med J, 2018, 8(2):254-259).

Materials and In this study, the files of 28 IEPHs diagnosed according to United Kingdom Parkinson's Disease Society Brain Bank (UKPDSBB) diagnostic Methods criteria and SAT were reviewed retrospectively in this study. Demographic data, age of onset of illness, duration of illness, Hoehn-Yahr stage (H\&Y), Unified Parkinson's Disease Rating Scale (UPDRS) motor scores, daily total off times, dyskinesia severity, daily total levodopa doses, apomorphine dose, duration of use were recorded and the values before and after SAT were compared with each other.

Results Sixteen patients were male and 12 were female. The average age at onset of disease was $63.4 \pm 4.9$ and duration illness was $10.1 \pm 2.8$ years. The mean daily total SAT dose was $53.5 \pm 18.9 \mathrm{mg}$ and duration of use was $17.6 \pm 9$ months. The mean off time was $4.4 \pm 1.6$ hours for neurological examination performed before treatment and mean off time was $1.1 \pm 0.3$ hours after treatment and there was statistically significant difference $(\rho<0,001)$. There was statistically significant difference in mean dyskinesia severity, UPDRS motor scores, mean levodopa doses in before and after treatment(respectively $p<0.001, p<0.001, p<0.001$,).

Conclusion SAT is effective in UPDRS scores, reduction of levodopa dose, shortening of off times, and reduction of dyskinesias in APPD.

Keywords Parkinsons Disease; apomorphine; off time; dyskinesia 
Sakarya TIp Dergisi 2018;8(2):254-259

\section{Giriş}

Parkinson hastalığı (PH), nigrostriatal yolakta dopaminerjik nöronların kaybına bağlı olarak oluşan, tremor, bradikinezi, rijidite ve postural denge bozuklukları ile karakterize, kronik ilerleyici nörodejeneratif bir bozukluktur. ${ }^{1}$ Ortalama olarak 60 ila 65 yaşları arasında başlar ve yaşa bağlı olarak ortaya çıkan ikinci en yaygın progresif nörodejeneratif hastalıktır. ${ }^{2}$ Parkinson hastalığının tedavisinde öncelikli tercih edilen ilaçlar Levodopa, Dopamin agonistleri, Katekol-O-metiltransferaz inhibitörleri, Monoamin oksidaz tip B inhibitörleridir. Dopamin prekürsörü olan levodopa ile tedaviye başladıktan kısa süre sonra (3 ila 5 yıl) diskinezi ve on/of fenomenini içeren motor dalgalanmaların görüldüğü illeri Evre Parkinson Hastalığın (IEPH)'da levodopanın etkililiğinin azalması yeni ilaçların geliştirilmesi için kapsamlı çalışmaların yapılmasıyla sonuçlanmıştır. ${ }^{3}$ Bu ilaçlardan biri de apomorfindir. Apomorfin morfinden elde edilmesine rağmen narkotik ve bağımlılık özelliği yoktur. Hem Dopamin 1 (D1) hem Dopamin 2 (D2) reseptörlerini aktive ettiği için dopaminin fizyolojik etkilerini en iyi taklit eden, non-ergo bir dopamin agonistidir. ${ }^{4-5}$ illk kez 1951 yılında PH'da tremor ve rijiditenin tedavisinde denenmiş ancak 1970’li yıllarda PH tedavisinde kullanılabileceği yapılan çalışmalarla gösterilmiştir. ${ }^{6}$ PH'da levodopa veya diğer dopamin agonistleriyle yapılan optimal tedaviye rağmen ortaya çıkan motor dalgalanmaların tedavisinde endikedir. ${ }^{7}$ Bu çalışmada kendi kliniğimizde son 5 yılda IEPH nedeni ile SAT uygulanan hastaların verileri sunulmaktadır.

\section{Gereç ve Yöntem:}

Bu Çalışmada 2012-2017 yılları arasında Sakarya Üniversitesi Eğitim ve Araştırma Hastanesi Nöroloji Kliniğine baş vuran, UKPDSBB tanı kriterlerine göre tanı konulan ve subkutan apomorfin tedavisi alan 28 IEPH'nın dosyaları retrospektif olarak incelendi. Tanısı kesin olmayan, takipler sırasında parkinsonizm tanısı alanlar çalışma dışında tutuldu. Hastaların yaş, cinsiyet gibi demografik verileri, hastalık başlama yaşı, hastalık süresi, uygulamadan hemen önce en iyi on döneminde yapılmış olan Hoehn-Yahr (H\&Y) evresi, UPDRS motor skorları, günlük total of süreleri, diskinezi şiddeti, günlük kullanılan total levodopa dozları kaydedildi. Daha sonra uygulamadan 1 hafta sonra poliklinik başvurularında en iyi on döneminde yapılmış nörolojik muayeneleri, UPRDS motor skorları, günlük total of süreleri, diskinezi şiddetleri, günlük total levodopa dozları, günlük total subkutan apomorfin dozu, kullanım süresi ve kullanım şekli kaydedildi. Uygulama öncesi ve sonrası değerler birbiri ile karşılaştırıldı.

Sakarya Üniversitesi Etik Kurulundan çalışma ile ilgili onay alınmıştır.

İstatistiksel yöntem: Verilerin analizinde değişkenlerin yüzde dağılımları alınmış, sürekli değişkenler için merkezi ve yaygınlık ölçütleri (ortalamaさstandart sapma) hesaplanmıştır. Değişkenlerin dağılımı kolmogorov simirnov test ile ölçülmüştür. Bağımlı nicel verilerin analizinde wilcoxon testi kullanılmıştır. İstatistiksel analizler SPSS 21.0 for Windows paket programı kullanılarak yapılmış, $p<0.05$ anlamlı olarak kabul edilmiştir.

\section{Bulgular:}

Çalışmaya alınan hasta sayısı 28 idi. Yaş ortalaması 73,7士6,2 idi. Hastaların 16'sı erkek, 12'si kadın cinsiyette idi. Ortalama hastalık başlama yaşı $63,4 \pm 4,9$, hastalık süresi $10,1 \pm 2,8$ yıl idi. Ortalama

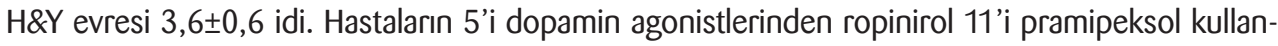
makta idi. Hastaların 15'i SAT’ı hala kullanıyorken 13'ü yan etkiler nedeni ile tedaviyi bırakmış idi. Yan etki olarak 10 hastada ciltte subkutan nödüller, 2 hastada şiddetli bulantı, 1 hastada hipotansi- 
yon gözlenmiştir. Ortalama günlük total subkutan apomorfin dozu 53,5 $\pm 18,9 \mathrm{mg}$, kullanım süresi $17,6 \pm 9$ ay idi. Hastaların 21 (\%75)'i infüzyon şeklinde subkutan apomorfin kullanırken 7 (\%25) hasta intermittan olarak kullanıyordu. Uygulama öncesi normal aktiviteyi engelleyen diskinezisi olan hasta sayısı $9(\% 32,1)$ iken şiddetli diskinezi olan hasta sayısı $19(\% 67,9)$ idi. Uygulama sonrası 24 $(\% 85,3)$ hastanın diskinezinde azalma görülürken 4 (\%14,2) hastada değişme olmadı. (Tablo 1)

\begin{tabular}{|c|c|c|c|c|c|}
\hline \multicolumn{6}{|c|}{ Tablo1:Hastaların demografik verileri, apomorfin dozu ve süresi ve diskinezi şiddeti } \\
\hline & & Min-Mak & Medyan & $\mathrm{n}-\%$ & Ort. \pm s.s. \\
\hline \multicolumn{2}{|l|}{ Yaş } & $62.0-85.0$ & 74.0 & & $73.7 \pm 6.2$ \\
\hline \multirow{2}{*}{ Cinsiyet } & Erkek & & & $15-55.6 \%$ & \\
\hline & Kadın & & & $12-44.4 \%$ & \\
\hline \multicolumn{2}{|l|}{ Hastalık Süresi } & $6.0-15.0$ & 10.0 & & $10.1 \pm 2.8$ \\
\hline \multicolumn{2}{|l|}{ Hastalık Başlama Yaşı } & $54.0-72.0$ & 64.0 & & $63.4 \pm 4.9$ \\
\hline \multicolumn{2}{|l|}{ Tedavi Öncesi HY } & 3.0- 5.0 & 4.0 & & $3.6 \pm 0.6$ \\
\hline \multicolumn{2}{|c|}{ Günlük Toplam Apomorfin Dozu } & $25.0-88.0$ & 50.0 & & $53.5 \pm 18.9$ \\
\hline \multicolumn{2}{|c|}{ Apomorfin Kullanım Süresi } & $6.0-46.0$ & 15.0 & & $17.6 \pm 9.0$ \\
\hline \multirow{2}{*}{ ApomorfinVeriliş Şekli } & İnfüzyon & & & $21-77.8 \%$ & \\
\hline & İntermittan & & & $6-22.2 \%$ & \\
\hline \multirow{2}{*}{ Tedavi Öncesi } & Normal Aktiviteyi Sınırlar & & & $9-33.3 \%$ & \\
\hline & Şiddetli & & & $18-66.7 \%$ & \\
\hline \multirow{2}{*}{$\begin{array}{l}\text { Tedavi Sonrası } \\
\text { Diskinezi }\end{array}$} & Azaldı & & & $4-14.8 \%$ & \\
\hline & Değişmedi & & & $23-85.2 \%$ & \\
\hline
\end{tabular}

Uygulama öncesi ortalama levodopa dozu $673,2 \pm 152,5 \mathrm{mg}$ iken uygulama sonrası ortalama levodopa dozu $372,2 \pm 96,4 \mathrm{mg}$, doz değişim yüzdesi ise \%44,1 saptanmıştır. Uygulama öncesi ve sonrası levodopa dozlarında istatistiksel olarak anlamlı fark saptanmıştır $(\rho<0,001)$. Uygulama öncesi yapılan nörolojik muayenede ortalama of süresi 4,4 $\pm 1,6$ saat iken uygulama sonrası ortalama of süresi $1,1 \pm 0,3$ saat, of sürelerindeki değişim yüzdesi $\% 73,3$ idi. Uygulama öncesi ve sonrası ortalama of süreleri karşışşıııldığında istatistiksel olarak anlamlı fark saptandı $(<0,0019)$. Uygulama öncesi en iyi on döneminde yapılan nörolojik muayene ve UPDRS motor skorları 32,9 $\pm 2,9$ iken uygulamadan 1 hafta sonra poliklinik başvurusunda en iyi on döneminde yapılan UPDRS motor skorları 19,5 51,7 , UPDRS motor skorlarındaki değişim yüzdesi \%40,4 idi. Tedavi öncesi ve tedavi sonrası UPDRS skorlarına bakıldığında anlamlı fark saptandı( $p<0,001)$. Uygulama öncesi diskinezi şiddeti ile uygulama sonrası diskinezi şiddeti karşılaştııılı̆̆ında istatistiksel olarak anlamlı fark saptandı $(p<0,001)$. (Tablo 2) (Şekil 1-2-3)

\section{Tartışma:}

Apomorfin levodopa'ya benzer etki gösteren dopamin reseptör agonistidir. Öncelikle D2 dopaminerjik reseptörleri üzerine etkilidir. Genellikle D2 reseptör agonistik aktivitenin semptomatik antiparkinson etkiyi oluşturduğu kabul edilmektedir. ${ }^{1}$ Parkinson hastalarında ani beklenmedik 'of' fenomenini kontrol etmede ve Levodopa ile ilişkili diskinezilerin kontrolünde kullanılır. Günümüzde apo-morfin subkütan enjeksiyon ile verilmekte ve semptomlar 20-30 dakikada hafiflemeye başlamaktadır. ${ }^{8}$ Yarılanma ömrü 45 dakikadır bu yüzden sürekli infüzyon yada intermittan olarak kullanııır. ${ }^{9}$ Yaklaşık 30 yıldır iEPH tedavisinde kullanılmaktadır ve etkinliği ile ilgili bir çok çalışma ya-
Sakarya Tıp Dergisi

$2018 ; 8(2): 254-259$

ARAS ve Ark.

ileri Evre Parkinson Hastaliğnda Subkutan

Apomortin Klinik Deneyimlerimiz 
Sakarya TIp Dergisi 2018;8(2):254-259 pılmıştır. García Ruiz ve ark. tarafından yapılan 82 hastalık çalışmada hastaların yaş ortalaması 67, hastalık süresi 14.3, ortalama günlük subkutan apomorfin dozu 72 mg ve kullanım süresi 19.93 ay olarak ölçülmüştür. Bizim çalışmamızda ise literatürler benzer olarak hastaların yaş ortalaması 73.7, ortalama hastalık süresi 10.1, ortalama günlük total subkutan apomorfin dozu 53,5 $\pm 18,9 \mathrm{mg}$, kullanım süresi 17,6 \pm 9 ay saptanmıştır. Yine aynı çalışmada uygulama öncesi ve sonrası levodopa doz değişimlerine baktığımızda uygulama sonrasında \%32.9 oranında ortalama levodopa dozunda azalma, ortalama günlük of sürelerinde $\% 79.51$ oranında azalma ve dizkinezi şiddetinde $\% 32.14$ oranında azalma saptanmıştır. ${ }^{10}$ Katzenschlager ve ark. 12 hasta üzerinde yaptığı çalışmada ortalama levodopa dozunda \%55 oranında azalma, ortalama günlük of sürelerinde $\% 38$ oranında azalma, ortalama diskinezi şiddetinde \%31 oranında azalma görülmüştür. ${ }^{11}$ Yine Morgante ve ark. tarafından yapılan ve 12 hastalık çalışmada uygulama öncesi ve sonrası ortalama levodopa dozlarında \%52 oranında azalma, ortalama günlük of sürelerinde $\% 60$ oranında azalma ve ortalama diskinezi şiddetinde $\% 48$ oranında azalma saptanmıştı. ${ }^{12}$ De Gaspari ve ark. tarafından ortalama H\&Y evresi 3-5 olan hastalar üzerinde yapılan çalışmada ise uygulama öncesi ve sonrası ortalama levodopa dozlarında \%29 oranında azalma, ortalama of sürelerinde $\% 51$ oranında azalma saptamışlar ancak diskinezi şiddetinde değişim gözlememişlerdir. ${ }^{13}$ Borgemeester ve ark. yaptığı çalışmada of sürelerinde belirgin kısalma on sürelerinde uzama saptanmış ancak diskinezide fark saptanmamıştır. ${ }^{14}$ Yine Sesar ve ark. 230 hastayı 10 yıl takip ettikleri çalışmasında subkutan apomorfin tedavisinin of sürelerini belirgin kısalttığ levodopa ve dopamin agonistlerinin dozunu azalttığı ve diskineziyi kötüleştirmediğini göstermişlerdir. ${ }^{15}$ üzerinde yaptığı ve Bizim çalışmamızda ise literatürle uyumlu olarak uygulama öncesi ve sonrası ortalama levodopa dozlarında \%\%44,1 oranında azalma, ortalama of sürelerinde $\% 73,3$ oranında azalma ve ortalama diskinezi şiddetinde \%57.5 oranında azalma saptanmıştı. Ayrıca uygulama öncesi ve sonrası ortalama levodopa dozları, ortalama günlük of süresi ve ortalama diskinezi şiddeti karşılaştıııldığında istatistiksel olarak anlamlı fark saptandı. Pfeiffer ve ark tarafından yapılan başka bir çalışmada en iyi on döneminde yapılan muayenedeki ortalama UPDRS motor skorlarında uygulama öncesi ve sonrası arasında istatistiksel olarak anlamlı fark saptanmış iken bizim çalışmamızda da anlamlı fark saptandı. ${ }^{16}$

\begin{tabular}{|c|c|c|c|c|c|}
\hline & Min-Mak & Medyan & Ort. \pm s.s. & & \\
\hline \multicolumn{6}{|c|}{ Levodopa Dozu (mg) } \\
\hline Uygulama Öncesi & $500,0-900,0$ & 600,0 & $673,1 \pm 152,5$ & \multirow{4}{*}{0,000} & \multirow{4}{*}{ w } \\
\hline Uygulama Sonrası & $250,0-600,0$ & 350,0 & $372,2 \pm 96,4$ & & \\
\hline Değişim Miktarı & $0,0-450,0$ & 300,0 & $300,9 \pm 103,7$ & & \\
\hline Değişim Oranı \% & $0,0 \%-58,0 \%$ & $48,0 \%$ & $44,1 \% \pm 11,3 \%$ & & \\
\hline \multicolumn{6}{|l|}{ OF Süresi (saat) } \\
\hline Uygulama Öncesi & $3,0-10,0$ & 4,0 & $4,4 \pm 1,6$ & \multirow{4}{*}{0,000} & \multirow{4}{*}{ w } \\
\hline UygulamaSonrası & $1,0-2,0$ & 1,0 & $1,1 \pm 0,3$ & & \\
\hline Değişim Miktarı & $2,0-8,0$ & 3,0 & $3,3 \pm 1,4$ & & \\
\hline Değişim Oranı \% & $60,0 \%-83,0 \%$ & $75,0 \%$ & $73,3 \% \pm 7,2 \%$ & & \\
\hline \multicolumn{6}{|l|}{ UPDRS Skoru } \\
\hline Uygulama Öncesi & $28,0-40,0$ & 33,0 & $32,9 \pm 2,9$ & \multirow{4}{*}{0,000} & \multirow{4}{*}{ w } \\
\hline Uygulama Sonrası & $15,0-23,0$ & 20,0 & $19,5 \pm 1,7$ & & \\
\hline Değişim Miktarı & $8,0-19,0$ & 14,0 & $13,4 \pm 2,8$ & & \\
\hline Değişim Oranı \% & $29,0 \%-56,0 \%$ & $41,0 \%$ & $40,4 \% \pm 6,3 \%$ & & \\
\hline
\end{tabular}




\begin{tabular}{|c|c|c|c|c|c|}
\hline & Min-Mak & Medyan & Ort. \pm s.s. & & \\
\hline \multicolumn{6}{|l|}{ Diskinezi şiddeti } \\
\hline Uygulama öncesi & $3,5-3,8$ & 3,7 & $3,6 \pm 0,5$ & \multirow{4}{*}{0,000} & \multirow{4}{*}{ w } \\
\hline Uygulama sonrası & $1,7-1,9$ & 1,9 & $1,9 \pm 0,4$ & & \\
\hline Değişim miktarı & $0,2-0,3$ & 0,2 & $0,2 \pm 0,1$ & & \\
\hline Değişim Oranı \% & $0,0 \%-75,4 \%$ & $62,1 \%$ & $57,5 \% \pm 9,9 \%$ & & \\
\hline
\end{tabular}
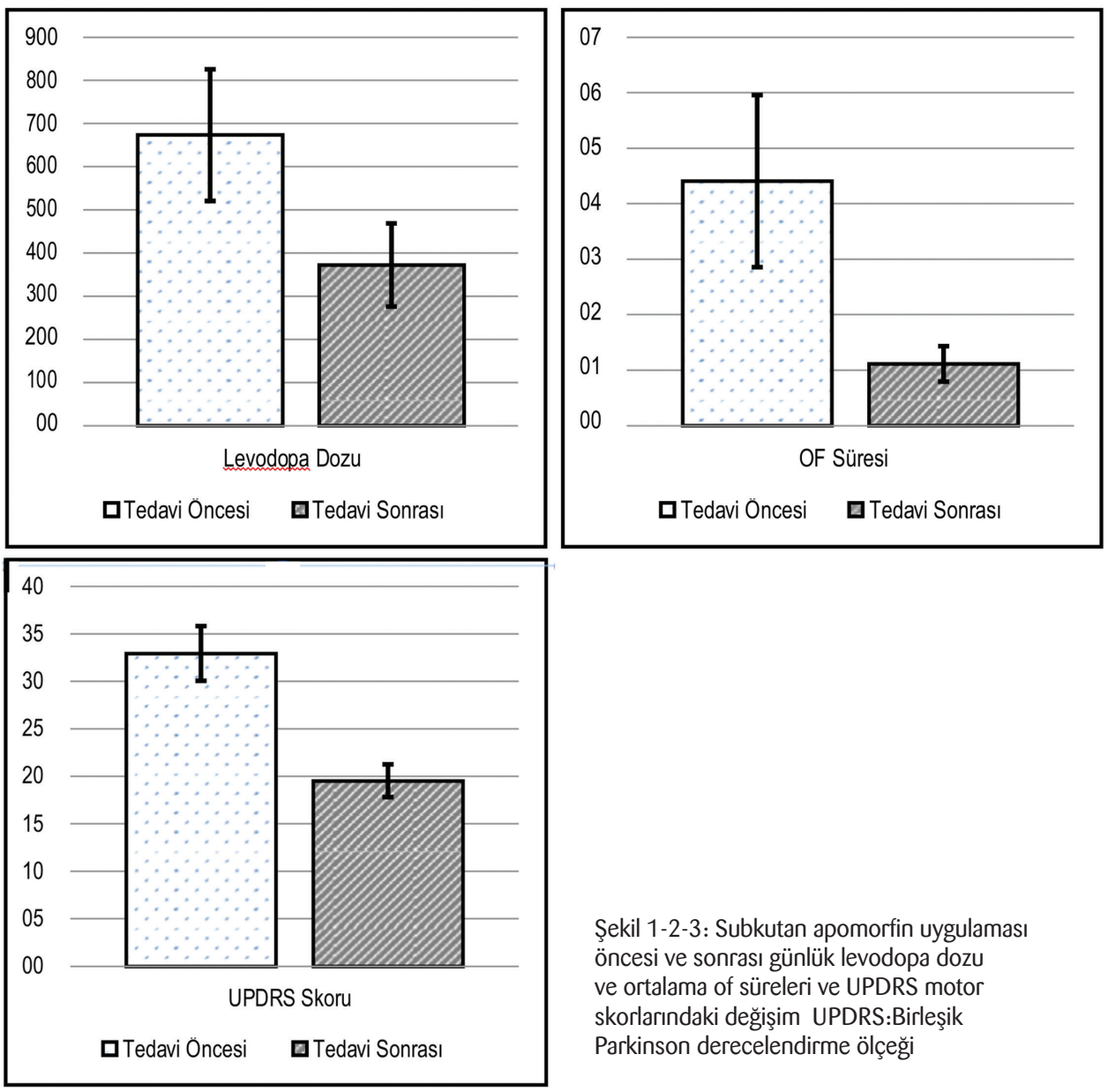

Şekil 1-2-3: Subkutan apomorfin uygulaması öncesi ve sonrası günlük levodopa dozu ve ortalama of süreleri ve UPDRS motor skorlarındaki değişim UPDRS:Birleşik Parkinson derecelendirme ölçeği

Sonuç olarak bu çalışmada daha önceki çalışmalarda da gösterildiği gibi iEPH'da SAT özellikle günlük ortalama levodopa dozlarını azaltmada, UPDRS motor skorlarını geriletmede, diskinezi şiddetini azaltmada ve günlük ortalama of sürelerini kısaltmada etkili olduğu gösterilmiştir. 
1. Yiğit G, Arıcıoğlu F. Günümüz ve Gelecekte Parkinson Hastalığı için Farma kolojik Tedavi Yaklaşımları. MÜSBED 2015;5(4):265-273 DOI: 10.5455/ musbed.20150827011840

2. Douglas MR. Gene therapy for Parkinson's disease: state-of-the-art treatments for neurodegenerative disease. Expert Rev Neurother. 2013;13(6):695-705

3. Connolly BS, Lang AE. Pharmacological treatment of Parkinson disease: a review. JAMA. 2014; 311(16):1670-83

4. Menon R, Stacy M. Apomorphine in the treatment of Parkinson's disease. Expert Opin Pharmacother. 2007;8(12):1941-1950

Sakarya Tıp Dergisi 2018;8(2):254-259
5. Dewey RB If 10 questions about using apomorphine for Parkinson disease. Neurologist. 2005;11(3):190-192. DOI:10.1097/01 nrl.0000159988.88538.74

6. Bhidayasiri R, Chaudhuri K.R, LeWitt P, Martin A, Boonpang K, et al. Effective Delivery of Apomorphine in the Management of Parkinson Disease: Practical Considerations for Clinicians and Parkinson Nurses Clin Neuropharm 2015;38:89-103.

7. Chen $\|$, Obering $C$. A review of intermittent subcutaneous apomorphine injections for the rescue management of motor fluctuations associated with advanced Parkinson's disease. Clin Ther. 2005 ;27(11):1710-1724.

8. Efficacy and Safety of APL-130277 in People with Parkinson's Disease who are Apomorphine Naïve. https:// www.michaeljfox.org/ foundation/ grant-detail.php?grant_id=1343.

9. Ossig C. Reichmann H. Treatment of Parkinson's disease in the advanced stage Neural Transm 2013;120:523-529 DOI 10.1007/s00702-013 1008-y.

10. García Ruiz PJ et al. Efficacy of long-term continuous subcutaneous apomorphine infusion in advanced Parkinson's disease with motor fluctuations: a multicenter study. Mov Disord. 2008; 23(8):1130-1136. doi 10.1002/mds.22063. PubMed PMID:18442107.
11. Katzenschlager R, Hughes A, Evans A, et al. Continuous subcutaneous apomorphine therapy improves dyskinesias in Parkinson's disease: a prospective study using single-dose challenges. Mov Disord 2005; $20: 151-1577$

12. Morgante L, Basile G, Epifanio A, et al. Continuous apomorphineinfusion (CAl) and neuropsychiatric disorders in patients with advanced Parkinson's disease: a follow-up of two years. Arch Gerontol Geriatr Suppl 2004;9:291-296

13. De Gaspari D, Siri C, Landi A, et al. Clinical and neuropsychological follow up at 12 months in patients with complicated Parkinson's disease treated with subcutaneous apomorphine infusion or deep brain stimulation of the subthalamic nucleus. J Neurol Neurosurg Psychiatry 2006;77:450-453.

14. Borgemeester RWK, van Laar T. Continuous subcutaneous apomorphine infusion in Parkinson's disease patients with cognitive dysfunction: A retrospective long-term follow-up study. Parkinsonism Relat $\mathrm{Di}$ sord.2017;45:33-38.doi:10.1016/j.parkreldis.2017.09.025.Epub 2017 Sep29

15. Sesar Á, Fernández-Pajarín G, Ares B, Rivas MT, Castro A. Continuous subcutaneous apomorphine infusion in advanced Parkinson's disease: 10-year experience with 230 patients. J Neurol. 2017;264(5):946-954. doi: 10.1007/s00415-017-8477-0. Epub 2017 Mar 31.

16. Pfeiffer RF, Gutmann L, Hull KL, Bottini B.P, Sherry J.H. The APO302 study Investigators. Continued efficacy and safety of subcutaneous apomorphine in patients with advanced Parkinson's disease. Parkinsonism and Related Disorders 2007:13:93-100 